\title{
Pío Baroja y su germanofilia en la conflictiva segunda década del siglo XX
}

\author{
Pío Baroja and his Germanophilia in the Troubled \\ Second Decade, XXth Century
}

\author{
Miguel Ángel García de Juan \\ IES Rosa Chacel (Madrid)
}

\section{RESUMEN}

Las páginas que siguen tratan de la germanofilia, que no germanomanía, de Pío Baroja, manifestada sobre todo a propósito de las negociaciones entre Francia y España respecto al reparto de Marruecos, tras la crisis de Agadir de 1911, y con ocasión de la Primera Guerra Mundial.

Para llevar a cabo el presente trabajo se ha acudido a las primeras estampaciones (alguna no localizada hasta ahora) de los artículos que publicó sobre esta cuestión en El Imparcial, España, $A B C$ y El Día, a lo largo de la segunda década del siglo pasado. A su vez, en el cotejo de las aludidas ediciones con sus reproducciones posteriores en antologías se ha advertido más de una variación significativa.

Se recogen y resumen, pues, aquí, por primera vez cronológicamente ordenados y contextualizados, después de haber descubierto todos los originales, aquellos artículos del escritor en los que explícita o tácitamente expone de manera argumentada su simpatía por la ciencia, la filosofía, la música, etc., alemanas en contraposición con los investigadores y la intelectualidad franceses.

Las discrepancias personales entre aliadófilos (o francómanos) y germanófilos (o germanómanos) durante la guerra mundial se transmitieron a los medios escritos, en ocasiones con gran virulencia, como se comprobará al recorrer el itinerario periodístico de Pío Baroja referido a su predilección por el mundo alemán, con la exclusión de su militarismo e imperialismo, frente al de nuestro vecino del norte, salvo en lo relacionado con la novela.

Palabras Clave: Pío Baroja; Alemania; Francia; germanofilia; aliadofilia; Marruecos; Primera Guerra Mundial.

\section{ABSTRACT}

The following pages are about the «germanophilia», but not «germanomania», in Pío Baroja, specially shown in relation with the negotiations between France and Spain with regard to the share of Morocco after de crisis in Agadir, 1911, and the occasion of the First World War.

In order to this work, we have considered the first printings, some of them unknown till now, of the newspaper articles published on that question in El Imparcial, España, $A B C$ and $E l$ Día, over the last century, second decade. On the other hand, remarkable variations have been borne in mind when considered the said editions in opposition to posteriors editions in anthologies. 
Here are collected and summarized for the first time in chronological order and in context, those articles where the writer tacitly or explicitly, sets out his sympathy towards the german science, philosophy, music, etc., in contrast to the french research and intelligentsia.

The personal discrepancies among the «aliadophiles» (or «francomaniacs») and the «germanophiles» (or «germanomaniacs») in the World War, were transferred to the print media, sometimes with virulence, as will be proved when following Pío Baroja's journalistic itinerary in relation with his predilection for the german world except for its militarism and imperialism, in opposition to our nothern neighbour's world except for its novel.

Key words: Pío Baroja; Germany; France; «germanophilia»; «aliadophilia»; Morocco; First World War.

Es de sobra conocida por estudiosos y lectores de Pío Baroja su preferencia por la filosofía, la música y la ciencia alemanas desde muy temprano, como lo demuestran sus artículos sobre el pensador Friedrich Nietzsche cuando el futuro escritor era aún muy joven: «Nietzsche y la filosofía» (Revista Nueva, 15 de febrero de 1899) y «Nietzsche íntimo» (EL Imparcial, 9 de septiembre y 7 de octubre de 1901). Con todo, la mayor influencia en sus obras hasta la frontera con el siglo XX provenía de A. Schopenhauer, filósofo de su predilección, juntamente con el anterior y Kant. El influjo de los pensadores alemanes citados perduró en sus ideas y obras literarias y no creativas hasta el final de su vida, así lo testifican las palabras de homenaje a Ortega y Gasset en el $A B C$ del 20 de octubre de 1955, con ocasión de su fallecimiento:

Como no tengo apenas responsabilidad escribo lo que pienso sobre los demás, sin ningún reparo, y si creo que Ortega era más de la raza de los grandes escritores que de los filósofos, lo digo con cierta alegría, porque los filósofos, en general, quitando a Schopenhauer y a Nietzsche, y tal vez algún otro, son un tanto pesados y poco agradables de leer ${ }^{1}$.

Si los nombrados ocupan el primer lugar entre sus pensadores predilectos, en el terreno de la música, los compositores más admirados fueron Schumann y Wagner junto a otras dos máximas figuras también germanas: «Lo más universal en música es, sin duda, la música alemana, sobre todo Mozart y Beethoven», dice en Juventud, egolatría (1917) (Baroja, 1997-1999, XIII: 347).

En cuanto a la ciencia, en no pocas ocasiones reconoció el trabajo, el rigor, la seriedad, la disciplina de los investigadores alemanes, quienes representan lo me-

\footnotetext{
${ }^{1}$ Para comprobar la influencia de Friedrich Nietzsche en Baroja, puede leerse Nietzsche en España 1890-1970, de Gonzalo Sobejano (2004: 62-64, 103-105 y 347-395). Por su parte, Ignacio Elizalde (1990: 49-56) afirma que quien más influyó en Baroja no fue Nietzsche sino el pesimista de Danzig. Félix Bello Vázquez dedica la mitad de su monografía de 1993 , a rastrear, en la obra del escritor vasco, las huellas de los tres pensadores alemanes citados. Sobre esta misma cuestión pueden consultarse también David Ordóñez García (1996: 139159), y Miguel Ángel García de Juan (1997: 109-114). Finalmente, es oportuno leer del propio Pío Baroja la parte cuarta del volumen I de sus «memorias» (1982-1983).
} 
jor en este campo. Así, para Baroja «el físico más célebre de nuestra época» es Max Planck ${ }^{2}$. No extraña, por tanto, que en la carta del 28 de octubre de 1935 enviada a su amigo Paul Schmitz le exponga que le ha escrito H. Demuth para pedirle información con el objeto de realizar un estudio sobre su obra y le diga: «El joven Demuth me escribió varias veces y le di ya las señas de Ud. Supongo que hará algo a la alemana, fuerte, bien documentado. Así tendrá uno la impresión de verse como un insecto clavado con un alfiler y con la clasificación correspondiente» (Baroja, 1997-1999, XVI: 1646).

Pero no fue absolutamente devoto de todo lo proveniente de Alemania, pues en el terreno literario sus preferencias se dirigieron hacia el mundo inglés, con Poe y Dickens; el ruso, con Gogol, Turguenev, Dostoievski y Tolstoi; el francés, con escritores del relieve de Verlaine, Balzac o Stendhal, a pesar de que en la siguiente cita no nombre precisamente a estos últimos:

Los que han demostrado imaginación en la Edad Moderna han sido las gentes del Norte: ingleses, alemanes, escandinavos y rusos: en literatura Defoe, Byron, Dickens, Poe, Heine, Ibsen, Dostoievski; en música Mozart, Beethoven, Schumann y Weber; en pintura el Bosco, Brueghel, Vermeer; en filosofía Kant, Schopenhauer, Nietzsche. La gente del sur no ha hecho nada más que repetir, sin añadir nada apreciable a lo hecho por ella en la antigüedad (Baroja, 1982-1983, V: 321).

Aun cuando Baroja no lo manifieste, quizá tuvo que ver algo esta especial mirada hacia Alemania con la información que ofrece Paloma Ortiz Urbina respecto a la repercusión en España de la ciencia y cultura de ese país:

A partir de los años ochenta del siglo XIX con Bismarck de canciller el Imperio alemán comienza a considerar la política de prensa como un medio posible para ganarse las simpatías internacionales. A partir de 1900, con la llegada de Von Bülow a la cancillería, el uso de la prensa como medio de influencia en España y, muy concretamente en Madrid, tomará un nuevo impulso (Ortiz de Urbina, 2004: 2).

La mencionada Paloma Ortiz de Urbina añade que algunas revistas ya venían difundiendo la literatura de Goethe, Schiller, Novalis y Heine (poeta de ascendencia judía reconocido por Baroja, como se ha visto en una cita anterior).

Lo cierto es que el mundo científico y cultural alemán se va abriendo paso en medio del predominio de lo francés. A este respecto un acontecimiento digno de consideración es la creación del Colegio Alemán de Madrid, el cual, por su prestigio, recibirá en sus aulas a hijos de personas de alto estatus social y político, entre ellos a los de Romanones y de Alcalá Zamora. «Este hecho revela la paradójica amalgama entre germanofilia cultural y germanofobia política, que sería característica dominante de numerosos destacados políticos, artistas e intelectuales madrileños a partir de 1914» (Ortiz de Urbi-

\footnotetext{
${ }^{2}$ «Las promesas de Oriente», El Norte de Castilla, 6 de febrero de 1938. El artículo puede leerse en Pío Baroja (2001: 171-180).
} 
na, 2004: 10). Y, puestos a matizar actitudes, porque es oportuno hacerlo, quizá hubiera que distinguir con Azorín entre germanófilos y germanómanos y entre francófilos y francómanos ${ }^{3}$. Así, a Pío Baroja habría que incluirlo en el primer grupo y a no pocos partidarios de Francia en el cuarto. Por otro lado, como dice Ortiz de Urbina, hubo un considerable número de aliadófilos que en el fondo mantenían algo o bastante de admiración por la cultura y la ciencia alemanas:

La mayoría de los intelectuales de peso españoles pertenecían [...] al bando aliadófilo [...]. Sin embargo, esto no fue obstáculo para que muchos de ellos se reconocieran, aunque con la boca pequeña, admiradores de la cultura y la ciencia alemanas. En palabras de Espadas Burgos, «una germanofilia cultural, a la que nunca renunciaron, era perfectamente compatible con una aliadofilia política dominante en la mayoría de ellos». Una gran parte de los intelectuales españoles se había formado en Alemania. Fernando de los Ríos había estudiado en Jena y Marburg; Ortega y Gasset en Marburg y Leipzig; García Morente también en Marburg y en Berlín; Julián Besteiro en Berlín, Leipzig y Munich (Ortiz de Urbina, 2007: 205) ${ }^{4}$.

Don Pío podría haber sido uno más de estos que se inclinaron hacia el bando aliado y haber mantenido su admiración por Alemania con la boca pequeña, pero su predisposición congénita a manifestarse con total libertad, aunque le ocasionara problemas, le originó ser calificado de germanófilo, pero con el significado de germanómano, por quienes se decantaron hacia el bando aliado, ya estuvieran en contra de lo alemán, ya fueran francófilos o francómanos.

Es cierto que el propio Baroja se declaró germanófilo (o sea, admirador de la ciencia y la cultura alemanas) y poco atraído por lo francés y, menos aún, por admiradores del país transpirenaico como Lerroux, Azaña, Blasco Ibáñez y otros.

La crítica de don Pío a la política francesa en la década que nos ocupa comienza con la crisis de Marruecos de 1911, cuando la llegada al puerto de Agadir de la cañonera alemana «Panther» el 1 de julio estuvo a punto de desencadenar la primera gran guerra, al enfrentarse los intereses alemanes y franceses en el continente africano ${ }^{5}$. A Baroja le desagradó el comportamiento de Francia respecto a España en las negociaciones del reparto de territorios de Marruecos y el 31 de agosto publicó en El Imparcial el artículo titulado «¿Con el latino o con el germano?»donde decía, al final, que pensaba que para nuestro país sería mejor que en Marruecos terminara dominando Alemania, porque «esto haría que la civilización germánica llegara a España por el Sur», aunque matizaba:

\footnotetext{
${ }^{3}$ Véase Azorín, «Germanofilia y germanomanía», $A B C .3$ de marzo de 1915.

${ }^{4}$ La división de los políticos españoles entre aliadófilos y germanófilos puede percibirse con la lectura de VV. AA. (1991: 80-101).

${ }^{5}$ Una síntesis de lo ocurrido en la crisis de Marruecos de 1911 puede leerse en Javier Paredes (2009: 472-473).
} 
La alianza política hecha por los gobiernos de España y Alemania, como desean los reaccionarios, podría traernos solamente la parte exterior de la Alemania actual, la parte de postura y baladronada del káiser, la parte de la Alemania de cuartel y de cuerpo de guardia, no la Alemania científica, organizadora e industrial, que es la que nosotros quisiéramos conocer e imitar. En este caso, la alianza, más que conveniente, sería perjudicial (Baroja, 1997-1999, XIII: 306).

A este artículo del escritor vasco contestó el plenamente francófilo, si no francómano, Martín Piñol (Manuel Azaña) con otro en La Correspondencia de España (11 de septiembre de 1911) titulado «Las arriesgadas proposiciones de Pío Baroja» en el que defendía que, si España debía aliarse con otro país, ese debiera ser Francia, y en tono burlesco se refería a «la resuelta pluma de Pío Baroja», al «gracioso desenfado» de su estilo y a «las amenidades» de su artículo.

Pero dejemos, por ahora, las colaboraciones periodísticas de don Pío en las que expresaba su reconocimiento de ciertas virtudes de Alemania y criticaba a Francia, para recordar otro hecho anterior que contribuyó, sin duda, a que Baroja se reafirmara en su posición germanófila frente a lo francés: el abandono del Partido Radical del francófilo Lerroux en el que había ingresado en 1909. Al mostrar don Alejandro una actitud condescendiente con el gobierno a propósito del fusilamiento del fogonero del guardacostas «Numancia» Antonio Sánchez Moya el 10 de agosto de 1911, Pío Baroja expresó su desacuerdo en una carta al diario El País, publicada el día siguiente de la ejecución con el título de «Latigazos de Baroja. Sálvese el que pueda»:

Sr. D. Roberto Castrovido:

Mi querido amigo: la actitud pasiva del partido republicano durante el desenvolvimiento de la tragedia de Cádiz, me impulsa a enviarle esta carta que agradeceré la publique usted en El País.

Nunca he creído que el partido republicano fuera a hacer la revolución, nunca lo he considerado como un organismo de progreso y cultura ni he podido convencerme de que sus hombres tengan alguna superioridad ética sobre los caciques monárquicos que van devorando España; pero sí creía que un partido tan numeroso, tan extenso, podría servir de freno a la crueldad y arbitrariedad de los gobiernos $[\ldots]$.

Y concluye:

Para mí la única eficacia que podría tener el partido republicano era impedir la barbarie del gobierno, defender algo al débil. ¿No la tiene? No quiero pertenecer a este partido; me separo de él para siempre.

Salúdale muy atentamente, es su amigo

Pío Baroja

Madrid, 10 de agosto 6

${ }^{6}$ Y añade El País, al final:

Baroja es algo superior a un novelista —el primero de los jóvenes—, es más que un literato, es un hombre. 
Llama la atención que tras el estallido de la Primera Guerra Mundial, Baroja abandonara el no alineado diario El Imparcial para pasar a formar parte de la redacción de la revista proaliada España, fundada por Ortega y Gasset en 1915, aunque mantuviera sus opiniones sobre Alemania y Francia. Transcurrido un tiempo, el escritor vasco comenzó a sentirse incómodo en una revista claramente comprometida con los aliados y, al llegar a la dirección a principios de 1916 el socialista Luis Araquistain, la abandonó.

Después de bastantes meses, los lectores del católico y monárquico $A B C$, verán, no sin asombro, la firma de Pío Baroja en este periódico, al que con toda probabilidad fue llevado por su amigo Azorín.

Finalmente, del asunto de la germanofilia y la aliadofilia se ocuparía Baroja en un artículo publicado por el periódico El Día titulado «Los mitos de los aliadófilos» (3 de noviembre de 1918), con el que terminaría la década de escritos periodísticos en los que trató de su predilección de lo germano frente a la poca simpatía por lo francés. Pero de estos vaivenes en el itinerario de colaboraciones en periódicos que traten del mismo asunto, nos ocuparemos, con más detalle, después.

A continuación inventariamos cronológicamente ordenados estos artículos, lo que no se había hecho hasta ahora, con el propósito de que su disposición y contextualización ayuden a comprender mejor su origen y contenido, y el discurrir del pensamiento de su autor.

Varios de estos textos fueron llevados a Nuevo tablado de Arlequín (1917), en concreto al apartado «Alrededor de la guerra», no muy bien ordenados, y otros encontraron acomodo en distintos lugares de sus libros recopilatorios o de diversas ediciones de sus obras completas:

«¿Con el latino o con el germano?», El Imparcial. 31 de agosto de 1911 (Nuevo tablado de Arlequín, 1917, en Baroja, 1997-1999, XIII: 304-306).

«España, Alemania y Francia», El Imparcial. 5 de septiembre de 1911 (Baroja, 1997-1999, XVI: 1241-1244).

«Examen de criterios», El Imparcial. 30 de octubre de 1911 (Baroja, 19971999, XVI: 1245-1247).

«Nuestra francofobia, nuestro españolismo», El Imparcial. 5 de enero de 1912 (N. T. de Arlequín, en Baroja, 1997-1999, XIII: 306-311).

«Nuestras energías (preocupaciones de principio de año)», El Imparcial. 20 de enero de 1913 (Baroja, 1997-1999, XVI: 1247-1250).

¿A qué apagar algunos de sus gritos? ¿A qué atenuar sus reflexiones? ¿A qué poner reparos a determinados cargos? No creemos profanar el impulso generoso, la bella explosión de un alma grande.

Ni siquiera decimos la vulgaridad consabida: «Sentimos la resolución del Sr. Baroja, y confiamos en que, meditándola seriamente, desistirá de realizarla». No, al menos Baroja, esté donde esté, siempre que piense en alta voz será de los nuestros.

Un grito de rabia, de horror y de asco es con la protesta de Cádiz, lo único hermoso, honrado y grande. 
«De un germanófilo a un suizo alemán», El Imparcial. 21 de octubre de 1914 (N. T. de Arlequín en Baroja, 1997-1999, XIII: 312-317).

«Cosas del momento», España. 26 de febrero de 1915 (N. T. de Arlequín en Baroja, 1997-1999, XIII: 330-331).

«La opinión de las mujeres españolas sobre la guerra», España. 5 de marzo de 1915 (N. T. de Arlequín en Baroja, 1997-1999, XIII: 320-322).

«Divagaciones actuales», España. 12 de marzo de 1915 (N. T. de Arlequín en Baroja, 1997-1999, XIII: 317-320).

«Lecochandegui el jovial», España. 9 de abril de 1915 (N. T. de Arlequín en Baroja, 1997-1999, XII: 220-224).

«Los germanófilos», ABC. 20 de noviembre de 1916 (N. T. de Arlequín en Baroja, 1997-1999, XIII: 322-326).

«Nuestra guerra civil», ABC. 14 de diciembre de 1916 (N. T. de Arlequín en Baroja, 1997-1999, XIII: 327-329).

«Los mitos de los aliadófilos (Notas para un ensayo de pirronismo sobre las ideas actuales)», El Día. 3 de noviembre de 1918 (Momentum Catastrophicum, 1919, en Baroja, 1997-1999, XIII: 683-689).

Durante la crisis de Marruecos de 1911 (julio-noviembre) aparecieron tres artículos de Baroja en los que defendía su inclinación hacia lo alemán frente a los partidarios de Francia.

En 1912 sólo publicó uno, pues, como dice en enero de 1913 en «Nuestras energías (preocupaciones de principio de año)», ha pasado un año buscando hechos del primer tercio del siglo XIX. Además, le han ocupado tiempo y desasosiego la compra de Itzea y la enfermedad (bronconeumonía) y muerte de su padre en Vera de Bidasoa. Por lo que a publicaciones de textos de creación se refiere, aparecen este año la novela El mundo es ansí y varias reproducciones de cuentos de Vidas sombrías en el diario El Socialista.

En 1913 únicamente se estampó un artículo sobre su escaso interés por lo que procediera de Francia, el citado «Nuestras energías [...]»; y es que había comenzado la redacción de la serie «Memorias de un hombre de acción» y había viajado a París para informarse acerca de su protagonista. De esta manera, publica El aprendiz de conspirador y El escuadrón del Brigante.

Como en los años anteriores, en 1914 tan solo vio la luz un artículo de don Pío que tratara de su germanofilia frente a su poca simpatía por lo francés. Quizá haya que buscar la causa en que, como dice la Guía de Pío Baroja. El mundo barojiano, 1914 «transcurre [...] con viajes de Madrid a Vera y con estancias en Irún y San Sebastián» (Caro Baroja, 1987: 23). En cuanto a la publicación de libros, salió de la imprenta Los caminos del mundo.

En 1915, al haber sido llevado por Ortega y Gasset como redactor de España, Baroja escribe numerosos artículos para la revista, cuatro de los cuales tratan de las diferentes posiciones frente a los bandos contendientes en la guerra mundial. 
En 1916, realiza un viaje por España con José Ortega y Gasset y publica dos artículos en $A B C$ sobre la germanofilia y la aliadofilia. En lo concerniente a sus libros, se editan La ruta del aventurero y La dama de Urtubi.

Llegado 1917, comienza a publicar sus obras en la recién creada editorial de su cuñado Rafael Caro Raggio, donde los primeros libros que se imprimen fueron Juventud, egolatría y Nuevo tablado de Arlequín; este, como ya se ha dicho, reunía algunos de los artículos enumerados más arriba. Sin embargo, no escribió, que sepamos, ningún artículo relacionado con la guerra.

La actividad de Baroja estuvo condicionada en 1918 por el viaje a Fraga con la intención de conseguir su candidatura a diputado en las Cortes ${ }^{7}$, objetivo que no logró, al no retirarse el candidato que competía con él. En el terreno de las publicaciones narrativas o libros recopilatorios cabe citar Páginas escogidas, Las horas solitarias (que reúne artículos de 1917), La veleta de Gastizar, Los caudillos de 1830, El cura Santa Cruz y su partida e Idilios y fantasías $^{8}$. Ya en noviembre, aparece estampado en El Día su último artículo relacionado con la guerra mundial «Los mitos de los aliadófilos [...]».

Varios artículos sobre la simpatía del autor por Alemania y el poco atractivo que significaba para él Francia son resultado, como se verá, de escritos o cartas previos que trataban de España en relación con los dos países mencionados o de crítica de su inclinación proalemana. Así, el primero, «¿Con el latino o con el germano?», nace con ocasión de un artículo en el diario francés Le Temps en el que se decía que, si España se alineaba con algún país, este debería ser Francia.

Interesa tener esto presente porque el escrito de Baroja en El Imparcial surge en el contexto del debate que venía manteniéndose en la prensa sobre con cuál de los países enfrentados por el reparto de África tenía que alinearse España. El aludido contexto del artículo desapareció al quedar eliminadas en su reproducción en Nuevo tablado de Arlequín, y ya para siempre, las palabras del comienzo del primer párrafo que destacamos en cursiva a continuación: «La cuestión de la hermandad latina, que traía El Imparcial de ayer, me parece una de las cuestiones capitales para España [...]».

Si se acude a ese número de El Imparcial, se encuentra algo más de una columna sin firma con el título «El artículo de Le Temps. La hermandad lati-

${ }^{7}$ El Sol del 17 de febrero de 1918 dice: «Pío Baroja candidato». «Un grupo de electores del distrito de Fraga (Huesca) pensó en presentar por aquel distrito a un hombre de ideas muy avanzadas. Utilizaron la amistad de un pintor de aquella región con otros pintores y críticos de las peñas de Madrid, y consiguieron que Pío Baroja accediera a ofrecer su nombre para luchar por el triunfo electoral. ¿Aviraneta se convertirá en diputado a Cortes? El escritor vasco no anda pobre en esperanzas. Anteanoche salió para Fraga, y ha prometido que, si consigue el acta, no será ciertamente el diputado que se distinga por la mudez».

${ }^{8}$ Hasta este trabajo no se había descubierto que el antetexto de «El charcutero (un episodio de la historia de los chapelaundis del Bidasoa)», cuarto componente de la antología Idilios y fantasías, se encuentra en parte en el diario El Sol del 9 de diciembre de 1917, página 5. 
na», cuyos dos primeros párrafos no dejan lugar a dudas respecto al pensamiento del periódico:

Desde las columnas de Le Temps, un colaborador, desconocido para nosotros, Augusto Brea, invita a España a una reconciliación, a una mayor intimidad con Francia, alejándose de la tentación germana. La importancia de este artículo, más que en su texto, está en el hecho de haber sido publicado por Le Temps, que durante estos últimos meses y hasta hace pocos días, mostraba una airada hostilidad contra España.

Sin duda Les Temps prepara una evolución de su criterio, lanzando antes la opinión particular de uno de los colaboradores. Por lo que tiene de conciliación, nosotros lo miramos con respeto; pero nos vemos obligados, por un sentimiento de sinceridad, a advertir al colega francés que es tarde; que en esta última prueba de desdén con que Francia nos trata se han roto los muy sutiles lazos de alianza franco-española que había creado, más que ninguna otra razón, la literatura francesa del pasado siglo. Y el símil de las hermanas latinas convence ya a muy poca gente en las clases directoras de la opinión española. Del pueblo, no digamos, porque en el pueblo español se conserva vivo un sentimiento tradicional, acaso atávico, bien contrario a esa supuesta hermandad con Francia9 .

Baroja, asiduo colaborador de El Imparcial en estas fechas, escribe un artículo en sintonía con la línea editorial del periódico, de modo que «¿Con el latino o con el germano?» (31 de agosto de 1911) critica la creencia de que exista la «raza latina», pues, tanto en Francia como en Italia como en España hay «braquicéfalos y dolicocéfalos, arios y semitas, celtas y germanos, griegos y mongoloides» (Baroja, 1997-1999, XIII: 304). «Ni la raza, ni el idio-

${ }^{9}$ El Imparcial. 30 de agosto de 1911, página 1. Transcribimos los párrafos tercero, cuarto y quinto:

España se dolerá siempre de que Francia no quiere conocernos, no quiere estudiarnos. Para sus gobernantes, para sus turistas, para sus literatos, seremos siempre la España pintoresca que describieron Gautier, Dumas y Sué, un poco más grandes que Montenegro o que Servia (sic), un poco más cultos que Bulgaria, un poco más amenos que Marruecos. En ese mismo artículo de Le Temps, en que se nos insta a la reconciliación, está la prueba. Se habla en él de nuestra Central de Telégrafos y de su sala reservada a los corresponsales de la prensa. Según este articulista, entre el incesante ir y venir a los pupitres óyese hablar por todas partes alemán. Se creería uno en Hamburgo, en Berlín, en Colonia. Basta reproducir las palabras para que se advierta, no su exageración, sino su notoria falsedad.

Ese desconocimiento de cómo somos resalta a través de la historia en las relaciones francoespañolas y engendra sucesos como la invasión napoleónica, en la que, desde Bonaparte al último de sus generales, caminan de sorpresa en sorpresa y de desengaño en desengaño.

En cambio, Alemania nos estudia seriamente: indaga en nuestra historia, traduce a nuestros dramaturgos y a nuestros novelistas, hace la bibliografía de nuestros incunables, no hecha por nosotros mismos; publica los estudios más completos que se conocen de Velázquez, del Greco y de Goya, estudia nuestra geología. Procura, en suma, conocernos; hacernos justicia desdeñando las leyendas de antaño, las fantasías de pandereta y los odios de sectario con que se nos ha falseado ante el mundo. 
ma, ni la religión unen a estos pueblos que se llaman latinos» (Baroja, 19971999, XIII: 305). Tampoco los une su carácter. Y refiriéndose a Francia, escribe algunos elogios que no se repetirán mucho: «Es un pueblo armónico, razonador, completo; sus hombres han brillado en todas las ramas del saber; han tenido constantemente sabios, artista, militares, filósofos, siempre en su justo medio» (Baroja, 1997-1999, XIII: 305).

Afirma Baroja que es difícil la unión de los latinos porque entre ellos hay recelo, desdén, odio..., o sea, falta «un fondo de simpatía» mutua. «Para mí la hermandad latina es un trasto viejo mandado recoger» (Baroja, 1997-1999, XIII: 305). Y se pregunta qué debe hacer España ante esta situación, a lo que responde que la experiencia de las alianzas con Francia e Inglaterra ha sido negativa; por tanto, si pudiera darse una relación natural con Alemania, sería lo mejor: «Hay un hecho muy significativo, y es que casi todos los países, incluso los latinos, a mayor germanización corresponde mayor civilización» (Baroja, 1997-1999, XIII: 306).

Si Alemania consiguiera dominar en Marruecos, al convertirse en frontera con España, esta saldría beneficiada. Pero hay que leer con cuidado estas afirmaciones de Pío Baroja, pues se refieren a una comunicación entre culturas y ciencias, no entre lo político y lo militar, porque, como hemos transcrito más arriba, «en este caso la alianza más que conveniente sería perjudicial».

«España, Alemania y Francia» (5 de septiembre de 1911) fue escrito, según su autor, como contestación a una carta en que se hacían objeciones al artículo anterior, carta firmada por «Un francés que amaba a España». El comunicante, para demostrar su tesis de la superioridad de Francia sobre Alemania, cita los descubrimientos de Pasteur, Roux, Chanlemesse y, con el objeto de disminuir los méritos de Alemania, nombra a personalidades de otros países. Baroja rebate esta creencia general en el país vecino por no ajustarse a la realidad, según su criterio, y pasa a detallar el progreso en la biología, la medicina, la aviación y la telegrafía en Alemania, para concluir con que «en casi todos los dominios del saber se ve al alemán por delante, inventando o pensando; al francés después, vistiendo y dando forma al pensamiento ajeno» (Baroja, 1997-1999, XVI: 1242). «Además, nosotros, yo, por lo menos, no negamos que Francia sea uno de los primeros países del mundo; pero no podemos creer que sea el único, como quieren los franceses» (Baroja, 1997-1999, XVI: 1243).

Manifiesta Baroja que el autor de la carta afirma que de buena gana dejaría a España la vecindad con Alemania, a lo que responde don Pío. «Nosotros la tomaríamos con gran contento» (Baroja, 1997-1999, XVI: 1243). Añade que en la relación intelectual entre Francia y Alemania, esta ha resultado siempre saqueada, y en cuanto a la de Francia con España, nosotros hemos salido siempre perdiendo:

Francia ha llamado a Velázquez el Lebrun español; a Murillo, el Lesuer español; a Goya, el Daumier español [...]. Ya estamos avisados; ya queremos enterarnos, 
con los medios pequeños de un país pobre; ya queremos ver con nuestros ojos y oír con nuestros oídos. Ya no nos darán un Cousin por un Kant, ni un Saint-Saëns por un Wagner, ni un Delacroix por un Goya, ni un Mauricio Barrès por un Nietzsche. Vamos a hacer nuestra clasificación; mala, probablemente, imperfecta; pero nuestra. Por eso queremos a Alemania: para que nos ayude a desafrancesarnos (Baroja, 1997-1999, XVI: 1244).

En «Examen de criterios» (30 de octubre de 1911), expone Baroja que, en el asunto de Marruecos ha habido y hay tres actitudes: la de los guerreros que desde una cómoda situación animan a la batalla para conquistar territorios, y cita al periodista de $A B C$ doctor Maestre (Tomás Maestre) ${ }^{10}$; la de los pacifistas por encima de todo ${ }^{11}$, y la de los que tienen un «criterio utilitario» en las negociaciones:

España debe ir a la negociación [con Francia] con un criterio utilitario puro, sin mezcla de tropos retóricos ni de palabrería de juegos florales. No hay nada feo ni deshonroso en esto. Francia y Alemania han chalaneado como cañís de la puerta de Toledo. Nosotros, más pequeños, podemos negociar también sin menoscabo de dignidad. [...] España debe examinar todas las soluciones y todas las posibilidades. Entre dos comerciantes que pactan, el que intenta hacer intervenir la caballerosidad y el honor en sus diferencias no prueba que es un hidalgo, sino que es un imbécil (Baroja, 1997-1999, XVI: 1247).

«Nuestra francofobia, nuestro españolismo» (5 de enero de 1912) es una respuesta a otro artículo de Le Temps que califica a la prensa española de

${ }^{10}$ Véase, a modo de ejemplo, su artículo «El conflicto europeo. ¡Ni neutrales ni con Francia!», ABC. 3 de julio de 1911, página 5.

Para contrastar las comedidas opiniones de Baroja sobre Francia con las del articulista del $A B C$ nombrado por el escritor vasco, se copian el primer párrafo y el último del artículo citado: En vano hemos pensado - ¡cándidos! - alguna vez que Francia prescindiera de su odio tradicional a España, siquiera no fuese más que por ajustar su conducta a su firma en un tratado. Nos engañamos por completo cuando tal cambio imaginamos. No; Francia es nuestra eterna enemiga de ayer, nuestra enemiga de hoy, nuestra enemiga de siempre [...].

Por lo tanto, nuestros soldados deben ocupar a Tetuán y a Uazan (sic) y correrse hasta la orilla derecha del Sebú, marcando así la extensión por el sur de nuestra zona marroquí del norte. Esta es la medida inmediata y que, a mi juicio, no admite demora.

${ }^{11}$ Léase la columna de El País del día 10 de julio de 1911, página 1, titulada «Lo de Agadir. Celos y temores», que comienza: «No hay que dar importancia a la actitud de una parte de la prensa francesa contra España, porque no responde a un movimiento de la opinión pública favorable a la aventura africana. El pueblo francés, en su mayor parte, odia el empeño de extensión por Marruecos y de apoyar a un sultán detestado por los marroquíes. Todo queda reducido a gritería de uno cuantos artículos y a noticias de informaciones tendenciosas que no impresionan a nadie ni de un lado ni de otro de los Pirineos». Y termina: «Es de esperar que, en definitiva, Europa se retire por completo de Marruecos, dejando que los mineros y los traficantes del interior se defiendan, organizándose militarmente, sin pretender que para enriquecerlos sacrifiquemos vidas y haciendas los españoles, los franceses, los alemanes y los ingleses». 
francófoba. El autor del aludido artículo es M. J. F. Juge, corresponsal del diario francés en España, quien a su vez había criticado otro anterior de Baroja, probablemente «¿Con el latino o con el germano?»

Lo primero que manifiesta don Pío es que, si Monsieur Juge se ajustase a la realidad, vería que en España no hay francofobia «sino que en el fondo hay un entusiasmo muy grande por Francia» (Baroja, 1997-1999, XIII: 307). Es verdad que los «reaccionarios» critican de Francia la separación de la Iglesia y el Estado y la secularización de la enseñanza, pero también es cierto que los republicanos en su admiración de lo francés han llegado a «los límites de lo grotesco» (Baroja, 1997-1999, XIII: 307). «Durante muchos años la vida española ha sido una copia servil de la francesa en ideas, en nombres, en todo» (Baroja, 1997-1999, XIII: 307). Añade Don Pío que es verdad que comienza a notarse una tendencia antifrancesa, pero muy leve; tal tendencia no nace «de considerar a Francia una nación sin importancia», pues «Francia es una gran nación, quizá la primera nación del mundo, pero creemos también que no ha fecundado a España, que no la ha servido, que no la ha ayudado» (Baroja, 1997-1999, XIII: 308), y la culpa no ha sido de la segunda.

Agrega el autor que, además de razones espirituales para el surgimiento de la francofobia, existen otras de tipo político, puesto que el país vecino nos ha aconsejado siempre mal en lo referido a las posesiones en Marruecos:

No ha sido un español sino un político de importancia, Jaurés, el que ha dado a entender últimamente que Francia nos ha empujado a la campaña de Melilla. Supongamos que no nos impulsó, que dio únicamente su consejo su permiso. Realmente no debemos agradecerle el favor. Gracias a ese permiso llevamos una campaña de miles de soldados muertos y cientos de miles de pesetas perdidos. En cambio, en Alcázar y Larache, Francia no solo no dio el visto bueno sino que se opuso, y se ocuparon estas dos ciudades a disgusto del gobierno francés, sin disparar un tiro y sin matar a un hombre (Baroja, 1997-1999, XIII: 309).

Afirma Baroja que los franceses están equivocados si creen que la francofobia nace del orgullo de los españoles, cuando la realidad es que el amor propio español no existe y añade que él no es partidario de un «patriotismo alabancioso y petulante» sino de corregir los defectos del país y de luchar por mejorar «en ciencia, en justicia y en humanidad». Y termina:

Si nosotros hoy sintiéramos este patriotismo activo, tendríamos que ser mucho más francófobos, mientras Francia sea como hasta ahora, el país que no nos comprende, que no nos entiende, que nos pinta como una cosa absurda y arqueológica; el país que nos da el consejo del enemigo, en vez de la indicación del amigo (Baroja, 1997-1999, XIII: 311).

En «Nuestras energías (preocupaciones de principio de año)» (20 de enero de 1913) dice el autor que ha estado un año investigando sobre tiempos pasados españoles y eso le ha servido para comprobar la diferencia de España de hace un siglo respecto a la actual. Entonces había una energía que hoy 
se ha perdido como en otros países ha desaparecido algo que poseían antes. Así, el prestigio de Francia

ha tenido una quiebra profunda al final del siglo XIX. París ha dominado en Europa desde tiempos de Luis XIV hasta el segundo Imperio [pero] hoy París no sugestiona [...]. París, capital del mundo, va volviendo a ser cada vez más París capital de Francia; quién sabe si llegará a ser capital de la Turena (Baroja, 19971999, XVI: 1248).

Italia, por su parte, también ha sufrido un proceso de debilitamiento. Y, en cuanto a España, ha perdido su energía, su ardor de tiempos pasados recientes; «En la primera mitad del siglo XIX tuvo el brío de los guerrilleros, ¿qué ha hecho de él? No lo sabemos. Se ha evaporado; como decía antes, se ha perdido sin apenas dejar rastro» (Baroja, 1997-1999, XVI: 1248).

Pasa don Pío a tratar de cómo, en su opinión, sobre todo la Europa meridional «va debilitándose, afeminándose, perdiendo jugo» (Baroja, 1997-1999, XVI: 1248), para concluir volviendo a referirse a España y afirmando pesimistamente que es difícil que recupere las energías que tuvo en épocas pasadas.

Antes de resumir «Carta de un germanófilo a un suizo alemán» (21 de octubre de 1914), comenzada ya la Gran Guerra, hay que señalar que descubrimos ahora su primera estampación en la prensa, que el título del artículo era en origen «De un germanófilo a un suizo alemán» y que, además, hubo un cambio significativo al ser trasladado de la página de El Imparcial a la antología Nuevo tratado de Arlequín, modificaciones que se han mantenido en todas las ediciones posteriores. La alteración segunda, la más significativa, consistió en eliminar en el párrafo décimo lo que señalamos a continuación en cursiva:

Estos clericales odian a Francia por haber separado la Iglesia y el Estado y no ven en Alemania nada más que militarismo y disciplina. Creían que los alemanes iban a tirar al entrar en Bruselas el monumento a Ferrer, cosa que a los alemanes les tiene sin cuidado como los habitantes de la luna.

La eliminación de esas dos líneas y media se debió a que la realidad fue muy otra, pues el ejército alemán al llegar a la capital de Bélgica derribó la estatua allí erigida en honor del intelectual anarquista español Francisco Ferrer Guardia. Esta grave equivocación de Baroja lo condujo a suprimir las referidas líneas del artículo cuando se estampó por segunda vez y en impresiones sucesivas ${ }^{12}$.

${ }^{12}$ En El País del 26 de enero de 1915 Arturo Mori escribe un artículo a tres columnas titulado «La estatua de Ferrer y los alemanes. Decía Pío Baroja...», en el que recuerda a don Pío que, así como confesó haberse equivocado al afiliarse al partido de Lerroux, debiera hacer ahora lo mismo: «[...] Baroja no contaba con eso que ha ocurrido ahora en Bruselas. Le ha engañado una vez más su imaginación de hombre del norte. El monumento a Ferrer repre- 
De nuevo don Pío declara que contesta a un escrito, en este caso a una carta personal «de un amigo suizo, en que habla de la guerra». Se trata del artículo en el que su autor se manifiesta más claramente a favor de la cultura y ciencia alemanas; por tanto, el texto que pudo granjearle en mayor medida la antipatía de los alidófilos. No obstante, como se verá, reparte por igual sus críticas a los unos y a los otros.

Ya en uno de los primeros párrafos muestra Baroja su deseo de que la guerra termine cuanto antes: «Yo espero que los sabios y los hombres ilustres lleguen poco a poco a entenderse y a influir en los políticos y militares para hacer la paz» (Baroja, 1997-1999, XIII: 312).

Y añade: «Usted quizá se pregunte por qué me siento germanófilo. Yo me siento germanófilo, naturalmente, más desde antes de la guerra que después de la guerra» (la cursiva es mía), pues su simpatía por lo alemán tiene su origen en el elevado número de intelectuales y científicos, mientras que su poco apego hacia Francia se debe, entre otras cosas, a no haber querido reconocer ni aprovechar los progresos de Alemania en la ciencia y en la cultura. Si París se hubiera abierto «a todas las tendencias universales hubiera llegado a ser la capital intelectual de Europa [...]. París no ha querido ser la ciudad europea, ha querido prescindir de Alemania, como si esto fuera posible, y ha ido construyéndose sobre sí misma, aceptando por credo las ideas ridículas y mezquinas de los nacionalista a lo Barrès» (Baroja, 19971999, XIII: 314).

Para Baroja a ninguno de los contendientes le asiste la razón, y menos «la necesidad de que Alemania, en este momento, tuviera que imponer a cañonazos su cultura, aunque esta sea superior a la de las demás naciones» (Baroja, 1997-1999, XIII: 315).

Critica el atropello de Bélgica por los germanos y sus aliados, pero recuerda que Francia e Inglaterra hicieron lo mismo en otros lugares del mundo como Egipto, Cochinchina, Marruecos, Madagascar, El Cabo, Nueva Zelanda, etc.

$\mathrm{Y}$, concluyendo con los reproches a unos y a otros, manifiesta:

Los alemanes intentan echar a los turcos a pelear con los rusos, Francia [...] paga a los senegaleses y a los argelinos para que mueran por ella [...]. Inglaterra trae a sus pobres esclavos de la India, a cuyos padres mató la boca de los cañones, a la línea de fuego [...]. El hombre salvaje y violento que todos llevamos dentro, el

sentaba un recuerdo solemne a la un día hollada libertad española, el testimonio de una vergüenza, de una política, sentina de políticas, que hoy condenan a coro el pueblo y el parlamento [...]». Y concluye: «Ahora bien, señor Baroja, maestro en letras castellanas. ¿No sería también noble, gallardo y solemne que, como otras veces, con mayor razón que otras veces, dijerais ante esta nueva escena que se abrió ayer para los ojos de nuestra alma inquieta y asombrada: "me he equivocado?"».

Las causas y consecuencias de la invasión de Bélgica por los alemanes pueden conocerse leyendo José Emilio Castelló (2010: 30-32). 
pitecantropus, el troglodita de Cromagnon o de Neandhertal ha salido de su cueva en pleno siglo XX (Baroja, 1997-1999, XIII: 316-317) ${ }^{13}$.

Que Baroja censuraba del mismo modo a los imperios centrales que a los países aliados lo prueba el hecho de que lo escogiera José Ortega y Gasset como colaborador de la fundada por él revista proaliada España, nada menos que como redactor, junto a él mismo y Maeztu, Ramón Pérez de Ayala, Luis de Zulueta, Eugenio D’Ors, Gregorio Martínez Sierra y Juan Guixééc.

En uno de los primeros números (26 de febrero de 1915), publica el escritor vasco «Cosas del momento», de nuevo un artículo a modo de diálogo con una persona real o ficticia; en este caso, su amigo el señor Duval, para quien «Francia es el país que lo ha descubierto todo: la navegación aérea, la submarina, la telegrafía sin hilos, el arte gótico» (Baroja, 1997-1999, XIII: 330), mientras que España no ha descubierto nada. Ante esta actitud, añade Baroja, terminará desapareciendo la amistad entre ambos.

Rebate la idea del antipático, para él, francófilo Blasco Ibáñez de que los descendientes de los «moros» españoles sean germanófilos porque le parece absurda. Luego se refiere al diario El País para afirmar que él no ha dicho que el triunfo alemán originaría una revolución sino que «la ideología alemana sería para nosotros más útil que la francesa, y, en general, la latina» (Baroja, 1997-1999, XIII: 331); y acaba con palabras de alabanza para Alemania, aunque tan exageradas como que si hay un país que pudiera «aplastar la Iglesia católica definitivamente es Alemania», igualmente, sería el único que pudiera acabar con los curas y frailes seguidores del viejo Jehová y con «la camama del parlamentarismo»; del mismo modo:

Si hay algún país que pueda acabar con la vieja retórica, con el viejo tradicionalismo español, soez y grosero, con toda la sarna semítica y latina, es Alemania. Si hay algún país que pueda sustituir los mitos de la religión, de la democracia, de la farsa de la caridad cristiana por la ciencia, por el orden y por la técnica, es Alemania (Baroja, 1997-1999, XIII: 331).

De nuevo escribe Baroja, con el pretexto real o simulado de haber recibido una carta, ahora de un señor de Barcelona, un artículo titulado «La opinión de las mujeres españolas sobre la guerra» (5 de marzo de 1915). El co-

13 «De un germanófilo a un suizo alemán» fue contestado críticamente pero con cortesía por el hispanista francés Alfred Morel-Fatio mediante dos entregas publicadas en La Correspondencia de España los días 16 y 17 de febrero de 1915.

El $A B C$ del 7 de enero de 1915 , página 8, recoge una carta de «Un lector de $A B C »$, en la que éste se suma a la opinión de Baroja respecto a sus simpatías hacia la Alemania, pero le critica que piense que él es el único germanófilo admirador de la filosofía, cultura, ciencia y música alemanas y contrario al imperialismo y militarismo germanos.

${ }^{14}$ Algunas precisiones acerca de la revista España. Semanario de la vida nacional y la relación de Baroja con ella pueden leerse en Miguel Sánchez-Ostiz (2006: 172-173). 
municante catalán le reprocha que en sus artículos mantenga ideas trasnochadas y que haga aseveraciones aventuradas.

Don Pío defiende que muchas de las mujeres de España no son aliadófilas, puesto que se inclinan hacia Alemania por dos razones: «primera, el amor a la fuerza; segunda, el entusiasmo por el orden»(Baroja, 1997-1999, XIII: 321):

Germanófilas, entusiastas del valor y de la guerra y al mismo tiempo — cosa algo paradójica- enemigas de la guerra así me han parecido la mayoría de las mujeres españolas. ¿Lo son de verdad? ¿Lo son todas? ¿Lo son sólo algunas? Yo no lo sé, señor de Barcelona. No quiero hacer afirmaciones categóricas (Baroja, 19971999, XIII: 322).

El autor se pronuncia contra la opinión de Schopenhauer de que las mujeres tienen el pelo largo y las ideas cortas, pues, si esto fuera así, habría que decirlo también de los hombres que se dejaran el pelo largo: «No creo en las ideas cortas de las mujeres. Idealismo, espiritualidad, sentido social es posible que les falte; pero inteligencia aguda creo que no» (Baroja, 1997-1999, XIII: 322). Y cierra este artículo, calificado de divagatorio por él, preguntándose por lo que pensará la mayoría de las mujeres españolas respecto a la guerra, pues lo que opinan las intelectuales que escriben y lo expresan públicamente no le interesa.

Si el artículo del que acabamos de tratar fue considerado por el autor como una «divagación» acerca de la actitud de las mujeres españolas ante la guerra, el siguiente lleva esa palabra al título, pues lo rotula «Divagaciones actuales» (12 de marzo de 1915).

Comienza Baroja diciendo que a las gentes de hace años «les parecía imposible una guerra como la actual» (Baroja, 1997-1999, XIII: 317), pues es cierto que las personas han evolucionado, pero la realidad indica que no tanto como para haber hecho desaparecer las confrontaciones armadas. Y, para explicar lo que ocurre cuando estas llegan, inventa un relato que tiene como protagonistas a los habitantes de Villavieja, Villacerca y Villalejos.

En Villavieja había dos bandos enfrentados, los conservadores, llamados «murales»y los progresistas, denominados «antimurales». De pronto estalló la guerra entre los dos últimos pueblos citados en el párrafo anterior y parecía lógico que los «antimurales» de Villavieja se situaran del lado de los que consideraban bárbaros lo villaviejenses y villacercanos; pero no fue así y todos los de Villavieja se volvieron defensores de los conservadores; más «murales» que nadie, pues en ese pueblo no estaban formados para la batalla. A este propósito comenta el autor: «Por muchas explicaciones que se quieran dar, este procedimiento de Villavieja me parece completamente absurdo» (Baroja, 1997-1999, XIII: 319). Tan absurdo como no preparase contra la guerra y, luego, tener que participar en ella le parece a Baroja le predicación en las iglesias del «No matarás» y al mismo tiempo la bendición de las armas mortíferas. 
Si este artículo era casi todo él una alegoría sobre el sinsentido de la guerra, el que examinamos a continuación es también una invención en clave de humor crítico respecto a la Primera Guerra Mundial, por eso «Lecochandegui el jovial» (9 de abril de 1915) ha sido considerado como un cuento y editado a veces sin contextualizar al margen de sus artículos hermanos en cuanto al contenido.

Lecochandegui, de profesión comisionista, era una persona muy habilidosa y con gran sentido del humor. «Leco», como lo llamaban familiarmente en Vera, decía que no entendía cómo la gente iba a misa a los escolapios, pues todos eran «carabineros retirados».

Una de las diversiones de Lecochandegui consistía en hablar de los inventos de los franceses y de los alemanes. De los primeros decía cenando una noche en Yanci que fabricaban unos polvos en Tarbes que dejaban a los enemigos muertos de pie; de los alemanes, que habían inventado «unos cañones que andaban por el aire, polvos que dejaban a uno desmayado, flechas con venenos... En aquel momento estaban construyendo unas trincheras en las nubes...» (Baroja, 1997-1999, XII: 222).

Pasado un tiempo, el autor-narrador del relato fue invitado por Leco a comer en su casa de Irún. Este, en el momento de servir la comida, animó a la muchacha a decir lo que él le había enseñado: «Hoy, diecisiete Thermidor. Libertad, Igualdad, Fraternidad», cosa que no hizo ninguna gracia a su mujer, quien reprochó a Leco que enseñase a la sirvienta esas tonterías, a lo que este respondió: «estoy completando la educación de la muchacha; le he enseñado el calendario republicano, y mi mujer no me lo agradece» (Baroja, 19971999, XII: 224). Cuando Lecochandegui decía estas cosas «seguía tan serio como siempre».

Pío Baroja abandona sus colaboraciones en la revista España en los primeros meses de 1916, al llegar el socialista Luis Araquistain a la dirección, y pasa a publicar sus artículos, dos de ellos sobre la guerra, en el diario $A B C$, probablemente por intermediación de su amigo aliadófilo Azorín, como ya se adelantó más arriba.

Antes de referirnos a estos dos artículos de Baroja, tiene interés recordar el agrio enfrentamiento mantenido entre la revista de la que se marchó y el periódico citado, de tendencia neutral en la Gran Guerra ${ }^{15}$.

En la página cinco del 2 de abril de 1915 Ramón Pérez de Ayala firma un artículo a tres columnas con el título de «Apostillas» en el que ataca duramente al $A B C$ y lo acusa de germanófilo, aunque su intención sea la de parecer no alineado. El periódico, sin responder a esta andanada, realiza para

${ }^{15}$ Cristina Barreiro, en la Revista Arbil, no 78 , expone que $A B C$ se propuso ser independiente $\mathrm{y}$, aunque tenido por germanófilo por los simpatizantes de los aliados, acogió en sus páginas firmas de los dos sectores: Juan Pujol del lado germanófilo y Azorín del aliadófilo. Véase la página $12 \mathrm{y}$, también, la 14. 
el 1 de junio una pregunta a diversas personalidades de la vida española, con ocasión de sus diez años de existencia. Con las respuestas a la pregunta «¿Qué opina usted de la labor realizada por el $A B C$ ?» el diario llenó ocho páginas, la primera de las cuales estaba encabezada por la contestación de Jacinto Benavente y la última la cerraba Francisco del Pino. Tan abundantes y significativos elogios debieron de caer muy mal en la revista España, la cual, en una columna sin firma de la página cuatro del 4 de junio, se preguntaba y respondía «¿Qué opina usted del «ABC»? «España» opina»:

Aunque no se ha requerido nuestra opinión, España se permite manifestarla, y es esta: Vemos, como todo el mundo en $A B C$, un magnífico alarde técnico que podría honrar a las artes gráficas de cualquier país, especialmente a España, donde, en general, las industrias van a la zaga del mundo.

Dicho esto, debemos confesar que ideológicamente es el $A B C$ el periódico más funesto de España, por haber patrocinado con gran eficacia, bajo el manto de la independencia, las causas más retrógradas y haber combatido las más liberales. Tras el señuelo de la independencia y de los grabados, han ido a beber incautamente muchos miles de lectores de $A B C$ doctrinas y tendencias lo más perniciosas para el progreso político de España, y en torno a sus arteras columnas se ha construido un núcleo de opinión pública que es hoy el más peligroso para el porvenir de España.

A tan agresivo escrito respondió el periódico atacado, que, dicho sea de paso, no sabemos que hubiera arremetido antes contra el semanario España, en la página décima del 6 de junio con «Una opinión sobre $A B C »$. Lo primero que manifiesta es que se trata de una revista desconocida por casi todos los lectores del periódico y que esta es una creación personal de José Ortega y Gasset: «Es la tribuna donde este joven metafísico y otros jóvenes escritores trascendentales, entristecidos por la decadencia nacional, vocean su melancolía y pregonan su desacuerdo con todo lo que les rodea». España, para este diario, es un intento, entre otros que aparecen de vez en cuando, que «representan la tradición de los antitradicionalistas y forman una parte curiosa y amena, la parte divertida de la Historia». Tras resumir a su manera el virulento escrito de España, concluye:

Podemos suscribir como una honrosa profesión de fe las tachas que nos pone el semanario España. Nuestra musa es eso que el colega llama desdeñosamente el nivel medio de la mentalidad española; el sentido de la multitud, el sentido común. Y no hay otro; para las cuestiones políticas no admiten otro las democracias, que, a nuestro juicio de reaccionarios, no han fracasado todavía.

La refriega continuó, pues el semanario respondió el 11 de junio con un suelto titulado «¿Qué opina VD. de «ABC»? «España» sigue opinando», al que respondió el diario, el 13 de junio, con un escrito a dos columnas bajo el marbete «Una réplica. La labor de $A B C$ » en el que dice que no quiere aburrir a los lectores con esta polémica y se defiende de la acusación a España de haber omitido el periódico en las respuestas del 1 de junio aquellas que le eran adversas. 
España volvió a la carga el 18 de junio de 1915 con un suelto titulado «"España” y “ABC”. Lo dicho, dicho» en el que exponía que la intención de la revista había sido reaccionar contra el cúmulo de halagos a $A B C$ del número del 1 de junio expresados por gente ligada al periódico e insistía en que, según la opinión extendida en nuestro país, « $A B C$ es uno de los periódicos españoles más vulgares, aunque vista levita [...], un periódico vulgar, órgano de la incultura bien trajeada». Después de añadir que da por cerrada la controversia, anuncia que, en el número siguiente, ella publicará la opinión que merece a los intelectuales españoles que no aparecieron en la larga lista de simpatizantes de $A B C$.

La contestación por parte del diario no se hizo esperar, puesto que respondió el 21 de junio con una «Nueva réplica para la revista «España»» en la que se defendía de las insinuaciones de recibir dinero por la crítica de libros, de obras de teatro o de corridas de toros y desafiaba al semanario a que demostrara lo contrario. Remachaba que quienes contestaron a su pregunta lo hicieron con absoluta libertad y concluía:

Los nombres que honraron nuestras páginas, entre los cuales figuran prestigiosos militares, políticos, artistas, periodistas, industriales, médicos, abogados y hombres de ciencias, están, por encima de lo que pueda decir este semanario de dómines engreídos, cuya vida languidece entre la indiferencia de lo que en España significa cultura y trabajo.

En esos momentos, entre los «dómines engreídos» de España, como los llama $A B C$, se encontraba todavía Baroja, quien después de marcharse de la revista a principios de 1916, por ironías de la vida, pasaría a publicar en este diario varios artículos, en el mencionado año y en 1917, de dos de los cuales nos ocupamos a continuación, por tratar ambos de la guerra mundial.

Pero antes de despedir a la revista España, quizá convenga añadir que esta siguió atacando a $A B C$ en otro suelto del 25 de junio que llevaba por título "“España” y "ABC". Lo dicho dicho y algo más» y acaso sea oportuno recordar que en la página seis del número del 9 de julio de 1915 publicó un «Manifiesto de adhesión a las naciones aliadas» y entre sus firmantes no aparecía, aún siendo redactor del semanario, el cual lamentaba «vivamente su ausencia», el nombre de Pío Baroja, como tampoco se adhirió, y esto, a pesar de ser enormemente significativo, se ignora u omite a sabiendas, al «Manifiesto germanófilo» publicado por El Imparcial el 17 de diciembre del mismo año. España, por supuesto, seguiría insertando en sus página manifiestos aliadófilos como el de la «Liga antigermanófila» del 18 de enero de 1917 (reproducido por el Heraldo de Madrid el día siguiente), o el de la «Unión democrática española. Para la Liga de la Sociedad de naciones libres» del 7 de noviembre de $1918^{16}$.

${ }^{16}$ En un artículo anterior nuestro, al seguir de cerca la información de Paul Aubert (1992: 117-123), dijimos erróneamente que el «manifiesto germanófilo» había aparecido en $E l$ 
El primer artículo de Baroja en $A B C$ que trata de la Gran Guerra lleva por título «Los germanófilos» (30 de noviembre de 1916).

Dice don Pío que ha estado ausente unos meses y que al reincorporarse a la lectura de la prensa francesa y española se encuentra con «los mismos lugares comunes que al principio de la guerra», o sea, que simpatizar con Francia e Inglaterra es prueba de progresismo y hacerlo con Alemania lo es de «conservadurismo y militarismo». Luego rebate la tradicional división latina entre izquierdas y derechas, la cual pudo servir en algún tiempo y en algunos lugares, pero no en las naciones del norte de Europa, donde no tiene cabida tal diferenciación. Se pregunta dónde habría que ubicar a Carlyle, Schopenhauer, Nietzsche, Ibsen, Dostoievski y Tolstoi; con todo, añade que aceptemos la tendencia de colocar a los germanófilos en la derecha y a los partidarios de Francia a la izquierda con el fin de ver si se corresponde con la realidad. No obstante, tanto unos como otros se han inclinado hacia la parte imperialista y militarista de los bandos contendientes, por lo que todos los aliadófilos y germanófilos se han convertido en conservadores y tradicionalistas. Así, pues, hay germanófilos como Benavente o Salaverría, pero también los hay como él mismo. A este propósito se interroga y responde sobre cuál es la diferencia entre unos germanófilos y otros, a los que, con Azorín, pudiéramos llamar germanómanos:

Ellos, los conservadores, ven en la germanofilia una cuestión meramente política; nosotros un problema de cultura y de organización industrial; ellos tienen un gran odio contra Inglaterra; nosotros una gran admiración por Inglaterra, que ha sido hasta hace años nación maestra; ellos creen que la política tradicional española ha sido necesaria y buena; ellos afirman que debemos ser optimistas con relación a España; nosotros afirmamos que mientras haya en nuestro país una extensión de páramos casi tan grande como toda Andalucía no tenemos derecho a dormirnos al arrullo de una retórica ridículamente optimista; ellos creen que España está hecha y consolidada; nosotros creemos que hay que hacerla; ellos suponen que basta conservar las viejas posiciones y abroquelarse en el pasado; nosotros deseamos reunir todas nuestras fuerzas y lanzarnos al porvenir... (Baroja, 1997-1999, XIII: 326).

\section{Y concluye:}

En nuestro país, la influencia germánica, la adopción de los procedimientos alemanes científicos, técnicos y mercantiles, sería el único modo de penetrar de lleno en el ciclo industrial, de acabar con todo dogmatismo, de limpiar el pensamiento español de viejas rutinas, de la elocuencia de los leguleyos, de nuestras fórmulas de retórica putrefacta.

\footnotetext{
Imparcial en agosto, cuando la realidad es que lo publicó este diario el 17 de diciembre de 1915. La Tribuna lo insertó también en sus páginas el 17 por la tarde. El día 19, El Imparcial estampa en la página 6 una larga lista de adheridos. Quien quisiera sumarse debía dirigirse a D. Manuel Guerrero Rodríguez, Calle Castelar número 2, Madrid.

Dice Cristina Barreiro en el artículo citado que fueron pocos los medios que no aceptaron dinero de un bando contendiente o de otro, entre ellos la revista España.
} 
El mes siguiente, el día 14, publica $A B C$ «Nuestra guerra civil» (14 de diciembre de 1916) en donde el escritor vasco afirma que desde el comienzo de la contienda tanto en España como en la mayoría de las naciones occidentales se ha producido una división en dos bandos. Al principio, francófilos y germanófilos se juntaban para discutir, pero ahora cada cual se reúne con su grupo y piensa que el que no coincide con él está en su contra: «Hace unos días estaba yo en Barcelona con los amigos aliadófilos. Un señor, dijo a uno de ellos: «Les hubiera invitado a ustedes a ver una casa artística de aquí cerca; pero como han venido ustedes con Baroja y Baroja es germanófilo, no los invito»». Añade, asimismo, que Azorín le respondió a un profesor de Kiel, que buscaba información para un editor alemán que deseaba traducir algunas obras españolas modernas, que no podía darle lo solicitado porque él era aliadófilo: «Yo decía a Azorín al saberlo que esto me parecía absurdo, anticultural y antihumano». Agrega don Pío que cada grupo cree que, si gana uno u otro bando, se verán colmados sus deseos, pero «las dos tendencias que hoy dividen a Europa en España, y, probablemente en todas partes, son espiritualmente dictatoriales» (Baroja, 1997-1999, XIII: 328).

Y termina:

Nuestra guerra civil podría ser un bien si una gran parte de los españoles se colocara en una actitud de expectación y de duda, suponiendo que podían tener razón y podían no tenerla. Creyendo cada cual que posee la verdad, toda la verdad, la verdad entera, nuestra guerra civil no puede tener eficacia para la cultura; ha de ser estéril, perfectamente estéril (Baroja, 1997-1999, XIII: 329).

A punto de acabar la guerra, ve la luz en el periódico El Día (3 de noviembre de 1918) «Los mitos de los aliadófilos (Notas para un ensayo de pirronismo sobre las ideas actuales)». La «guerra civil» en España a la que se refiere Baroja, derivada de la mundial, también tuvo lugar entre los medios de comunicación, como hemos visto ya a propósito del enfrentamiento entre España y $A B C$. Pues bien, ahora es Los Aliados, revista antigermanófila creada por y para la guerra por el bando aliado y con dinero de este ${ }^{17}$, la que ataca al periódico $E l D_{i} a^{18}$, rotativo en el que apareció el mencionado

${ }^{17}$ Los Aliados se publicó entre el 13 de julio de 1918 y el 30 de noviembre de ese mismo año, es decir, desapareció recién acabada la guerra. Entre quienes iban a escribir en sus páginas, según la dirección, se encontraban Luis Araquistain, Alejandro Lerroux, Ramiro de Maeztu, Miguel de Unamuno, Valle-Inclán y Ortega y Gasset, el cual, al verse incluido sin su autorización, escribió a la revista para que lo retiraran de la lista de colaboradores. La relación de esta revista con los EE. UU. de Norteamérica es indudable, si se fija la atención en el contenido de las informaciones y opiniones y también en la publicidad. El citado país había entrado en la guerra junto a los aliados el 6 de abril de 1917.

${ }^{18}$ Una de las embestidas de Los Aliados contra El Día, periódico del entorno de Niceto Alcalá Zamora, puede leerse en el número del 21 de agosto de 1918: «Germanófilos sin disfraz», página 3; artículo firmado por Antonio de Lezama (Antonio de Lezama González, 1888-1971, una de firmas más frecuentes en la revista, ejerció el periodismo y la política. 
artículo de Pío Baroja, el último de don Pío centrado en la Primera Guerra Mundial. La actitud de Los Aliados fue tanto o más agresiva que la de Espa$\tilde{n} a$ con quienes no defendían sus mismas ideas, pues llegó a declarar sin ambages que los proalemanes Vázquez de Mella y Armando Guerra (seudónimo este del colaborador de $A B C$ el teniente coronel de Estado Mayor Francisco Martín Llorente) debían suicidarse.

En el artículo Pío Baroja se fija en la brutalidad natural de las personas, algo de lo que ya había tratado en otros anteriores, a pesar de los mitos que habitan en el seno de las religiones, los grupos sociales, los países, etc. Por eso piensa el escéptico autor de «Los mitos de los aliadófilos [...]» que hay una serie de creencias entre los aliados que no se ajustan a la realidad; en consecuencia, deben ser combatidas.

«El primer mito puesto en circulación por los aliadófilos es la crueldad y la barbarie exclusiva de los alemanes»; El segundo el del «militarismo [igualmente] exclusivo de los alemanes»; el tercero, el de que Alsacia y Lorena son territorios franceses; el siguiente, que el káiser era el responsable de todo lo que ocurría en Alemania: en la ciencia, en el arte y en la literatura. Otro mito de reciente aparición entre los aliados era el de considerar al presidente norteamericano Wilson un ser vestido «con una túnica blanca, limpio de todos los pecados humanos, lleno de unción evangélica». Baroja piensa que esta simplificación maniquea de buenos y malos no se sostiene:

¿Ignoran esto los políticos? ¡Ca! Seguramente lo saben, pero les conviene lanzar mitos y hacer que el gran pueblo se trague grandes píldoras.

La hipocresía reina en la política aliadófila, desde arriba hasta abajo; así como la germanófila ha sido la política de militar torpe y bárbara, la aliadófila es política de comerciante y de cuco.

Y añade:

Ciertamente, este momento no es el más a propósito, desde el punto de vista personal y político, para hablar de los mitos aliadófilos (sic).

El éxito de los aliados en la guerra es evidente y sus representantes en España cantan victoria, y, si pudieran, tomarían represalias [...].

Para los que no dependemos del público ni nos importa el ambiente periodístico, la opinión general no nos intranquiliza. Hay que nadar contra corriente; eso es todo ${ }^{19}$.

Comenzó escribiendo en El Liberal. Se declaró aliadófilo durante la guerra. En 1919, cuando ya no existía Los Aliados fundó el periódico radical socialista La Libertad. Militó en la masonería y llegó a alcanzar el grado 33). Ya en un artículo anterior pusimos en cuestión la condición de germanófilo de El Día, pues en él colaboraban, cuando se publicó «Los mitos de los aliadófilos [...]» de Baroja, Emilio Carrere, Rafael Altamira...y Miguel de Unamuno, quien había firmado en 1915 el «Manifiesto de adhesión a las naciones aliadas» y que, precisamente, el 13 de julio de 1918 había escrito en Los Aliados un ardoroso artículo antigermano titulado «España protegida», páginas 3 y 4 .

${ }^{19}$ Algunos de estos artículos han sido comentados por José-Carlos Mainer (2012: 129-131). 
Como expusimos en otro lugar (García de Juan, 2012), el artículo fue duramente criticado por la revista España, en la que había colaborado don Pío desde su fundación en 1915 hasta comienzos de 1916. Añadimos ahora que, según acabamos de descubrir, también se le atacó desde Los Aliados en la página quinta del 9 de noviembre de 1918, donde, entre alabanzas a los «yanquis» y al presidente Wilson, Antonio de Lezama decía en los dos últimos párrafos de su «Pío Baroja Paradox»:

Cumbre de la intelectualidad, literato meritísimo, pensador y político ( $i$ !) de ideas avanzadísimas, gran novelista, tenía para mí Pío Baroja todas las cualidades que admiro en un hombre; pero este ídolo se ha desmoronado al leer un artículo que el escritor radical publicó en el órgano de la bochofilia, El Día, bajo el título «Los mitos aliadófilos (sic): Notas para un ensayo de prirronismo sobre las ideas actuales» [...].

¡Maestro, quítese usted la venda de los ojos y, si la suerte no le ha dado la clarividencia necesaria para ver los problemas sociales e internacionales, confórmese, que ello es ya bastante glorioso y envidiable, con escribir obras como La casa de Aizgorri y El mayorazgo de Labraz. Otra cosa es indigna de su talento ${ }^{20}$.

Cuando en 1919 reprodujo don Pío este artículo al final del opúsculo Momentum catastrophicum dejó zanjada la cuestión de su germanofilia y la manera expresarla con absoluta libertad, como hizo siempre con cualquier asunto, a pesar de que le ocasionase enemistades y hasta improperios:

Me han dicho que algunos periódicos, a sueldo de embajadas aliadas, contestaron a este artículo insultándome. No es cosa que me importe. Ni siquiera he leído esos insultos. No todo el mundo puede vivir de su trabajo y mucha gente tiene que vivir de la adulación. El oficio de criado es cómodo pero tiene sus fealdades; el ser hombre independiente es, a veces incómodo, pero tiene sus satisfacciones. Yo he elegido el ser hombre independiente y los insultos de los criados no me hacen mucha mella (Baroja, 1919: 89-90).

En conclusión, Pío Baroja, tanto a propósito de los dos significados bandos formados en España con ocasión de la Primera Guerra Mundial como en otras coyunturas siguió un camino propio, a pesar de que ello representara encontrarse en minoría y sufrir acerados y malintencionados reproches como el de germanófilo con el significado de germanómano a la manera de Benavente o Salaverría, y esto, aunque se hubiera declarado en contra del imperialismo y militarismo germanos y no hubiera firmado ninguno de los manifiestos que se publicaron a favor de los imperios centrales.

Es cierto que, a veces, por simplificación o por obstinación pudo cometer errores en su conducta y opiniones, pero su guía fue siempre el criterio personal, no el de otros ni, menos aún, el de la masa; así lo reconocía en plena

${ }^{20}$ «bochofilia» es un derivado de la palabra de origen francés boche, 'cabeza cuadrada'. «Designa peyorativamente al soldado alemán de la Primera Guerra Mundial». Véase Arturo del Hoyo (1995: 53-54). 
guerra Manuel Galán Pacheco en el diario proaliado El Sol (17 de febrero de 1918) en un artículo referido a Baroja encabezado por el elocuente título de «Un hombre libre».

\section{BIBLIOGRAFÍA CITADA}

Aubert, Paul (1992). Les espagnols et L'Europe (1890-1919). Toulouse: Presses Universitaires du Mirail.

Baroja, Pío (1919). Momentum catastrophicum. Madrid: Caro Raggio.

Baroja, Pío (1982-1983). Desde la última vuelta del camino, memorias. Madrid: Caro Raggio, 7 vols.

Baroja, Pío (1997-1999). Obras completas. José-Carlos Mainer (dir.); Juan Carlos Ara Torralba (revisión de textos). Barcelona: Círculo de Lectores, 16 vols.

Baroja, Pío (2001). Libertad frente a sumisión. Miguel Ángel García de Juan (ed., pról. y notas). Madrid: Caro Raggio.

Barreiro, Cristina. «La prensa española ante la primera Guerra Mundial», Revista Arbil [en línea]. 78, pp. 1-18. En: www.arbil.org/(78)cris.htm [ref. de 31/03/2015]

Bello Vázquez, Félix (1993). Pío Baroja: el hombre y el filósofo. Salamanca: Universidad de Salamanca.

Caro Baroja, Pío (1987). Guía de Pío Baroja. El mundo barojiano. Madrid: Caro RaggioCátedra.

Castelló, José Emilio (2010). La Primera guerra Mundial. La Gran Guerra. Madrid: Anaya.

Elizalde, Ignacio (1990). «Baroja y su ideología filosófica», Anuario de la Sociedad Española de Literatura comparada. VIII, pp. 49-56.

García de Juan, Miguel Ángel (1997). Los cuentos de Pío Baroja: creación, recepción y discurso. Madrid: Pliegos.

García de Juan, Miguel Ángel (2012). «Pío Baroja: nuevas aportaciones y aclaraciones a su obra, ideas y personalidad $(1918,1931,1936) »$, Letras de Deusto. Julio-septiembre, 136, pp. 185-205.

Hoyo, Arturo del (1995). Diccionario de palabras y frases extranjeras. Madrid: Aguilar.

Mainer, José-Carlos (2012). Pío Baroja. Madrid: Taurus-Fundación Juan March.

Ordóñez García, David (1996). «Baroja y Schopenhauer: implicaciones narrativas del mundo como representación», Anales de literatura española. 12, pp. 139-159.

Ortiz de Urbina, Paloma (2004). «El papel de la prensa diaria madrileña en la difusión de la lengua y cultura germánicas 1900-1914», Estudios interdisciplinares sobre lenguas modernas. Madrid: Servicio de publicaciones de la Fundación Universitaria San PabloCEU, pp. 1-14.

Ortiz de Urbina, Paloma (2007). «La primera guerra mundial y sus consecuencias. La imagen de Alemania en España a partir de 1914», Revista de Filología Alemana. 15, pp. 193-206.

Paredes, Javier (coord.) (2009). Historia universal contemporánea, I. Barcelona: Ariel.

Sánchez-Ostiz, Miguel (2006). Pío Baroja, a escena. Madrid: Espasa Calpe.

Sobejano, Gonzalo (2004). Nietzsche en España 1890-1970. Madrid: Gredos.

VV. AA. (1991). Historia de España, Alfonso XIII y la Segunda república (1902-1939), 11. Barcelona: Planeta.

Fecha de recepción: 6 de junio de 2013.

Fecha de aceptación: 8 de enero de 2014. 